Revista Universo Contábil, ISSN 1809-3337

Blumenau, v. 14, n. 2, p. 82-99, abr./jun., 2018

doi:10.4270/ruc.2018212

Disponível em www.furb.br/universocontabil

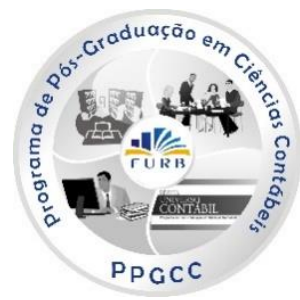

\title{
TRÊS VISÕES SOBRE ÉTICA E EVASÃO FISCAL: COMO SE POSICIONAM OS ESTUDANTES DA ÁREA DE NEGÓCIOS? ${ }^{1}$
}

\section{THREE VIEWS ON ETHICS AND TAX EVASION: HOW ARE BUSINESS STUDENTS POSITIONED? \\ TRES VISIONES SOBRE ÉTICA Y EVASIÓN FISCAL: ¿CÓMO SE POSICIONAN LOS ESTUDIANTES DEL ÁREA DE NEGOCIOS?}

\author{
Felipe Rodrigues Cruz \\ Mestrando em Ciências Contábeis pela Universidade Federal de Minas Gerais \\ Endereço: Avenida Presidente Antônio Carlos, 6627 - Pampulha \\ CEP: 31270-901 - Belo Horizonte - MG - Brasil \\ E-mail: felipe.rcruz11@gmail.com \\ Telefone: (31) 3409-7263/7069 \\ Ana Clara Ventura Paiva \\ Mestranda em Ciências Contábeis pela Universidade Federal de Minas Gerais \\ Endereço: Avenida Presidente Antônio Carlos, 6627 - Pampulha \\ CEP: 31270-901 - Belo Horizonte - MG - Brasi \\ E-mail: anaclaravp@gmail.com \\ Telefone: (31) 3409-7263/7069
}

Jacqueline Veneroso Alves da Cunha

Doutora em Ciências Contábeis pela Universidade de São Paulo Professora do PPG em Contabilidade e Controladoria da Universidade Federal de Minas Gerais Endereço: Avenida Presidente Antônio Carlos, 6627 - Pampulha CEP: 31270-901 - Belo Horizonte - MG - Brasil E-mail: jvac@face.ufmg.br Telefone: (31) 3409-7275

João Estevão Barbosa Neto

Doutor em Ciências Contábeis pela Universidade de São Paulo Professor do PPG em Contabilidade e Controladoria da Universidade Federal de Minas Gerais Endereço: Avenida Presidente Antônio Carlos, 6627 - Pampulha CEP: 31270-901 - Belo Horizonte - MG - Brasil E-mail: joaoestevaobarbosaneto@gmail.com Telefone: (31) 3409-7205

\footnotetext{
${ }^{1}$ Artigo recebido em 06/10/2017. Revisado por pares em 07/12/2018. Reformulado em 17/12/2018. Recomendado para publicação em 24/01/2019 por Marcia Zanievicz Silva. Publicado em 20/02/2019. Organização responsável pelo periódico: FURB.
} 


\section{RESUMO}

A evasão fiscal é um problema comportamental que ameaça a capacidade do governo de levantar receitas. Porém, ainda são poucos os trabalhos que examinam a não-conformidade com as obrigações tributárias sob um olhar ético. $\mathrm{Na}$ literatura sobre o tema, emergiram três visões relacionadas à ética da evasão fiscal. A primeira assume que a evasão nunca é ética. A segunda assume que a evasão é sempre ou quase sempre ética. A terceira visão está associada à noção de que a evasão não é absolutamente antiética. Nesse sentido, o presente trabalho teve por objetivo investigar como 195 estudantes dos cursos de Administração, Ciências Contábeis e Economia de Universidades Federais de Minas Gerais se posicionam em relação a essas três visões, partindo do modelo de McGee, Ho e Li (2008), que apresenta 15 afirmações sobre a evasão fiscal. Os estudantes foram classificados de acordo com sua visão por meio de uma análise de cluster e analisaram-se as associações de variáveis como idade, sexo, etc. com cada um dos grupos formados. Após a realização de uma análise de cluster, constatou-se que a maioria dos estudantes foi posicionada no grupo que considera a evasão como sempre antiética, enquanto a menor parte considera a evasão como ética. Constatou-se que as mulheres são menos propensas à evasão fiscal e que indivíduos de maiores faixas de idade são menos propensos a enxergar a evasão como ética. Em relação aos cursos, percebeu-se que os alunos de Ciências Contábeis são menos propensos à evasão fiscal em relação aos alunos dos cursos de Administração e Ciências Econômicas. Por fim, sintetizaram-se as visões de cada um dos grupos por meio da análise do Discurso do Sujeito Coletivo.

Palavras-chave: Ética; Evasão Fiscal; Estudantes da Área de Negócios.

\section{ABSTRACT}

Tax evasion is a behavioral problem that threatens the government's ability to raise revenue. However, there are still few papers that examine non-compliance with tax obligations under an ethical perspective. In the literature on the subject, three views related to the ethics of tax evasion emerged. The first one assumes that evasion is never ethical. The second assumes that evasion is always or almost always ethical. The third view is associated with the notion that evasion is not absolutely unethical. In this sense, this study aimed to investigate how 195 students from the courses of Business Management, Accounting and Economics of Federal Universities of Minas Gerais are positioned among these three views, starting from the model of McGee, Ho and Li (2008), which presents 15 statements on tax evasion. The students were classified according to their vision through a cluster analysis and the associations of variables such as age, gender, etc. with each of the groups formed were analyzed. After a cluster analysis, it was found that most of the students were positioned in the group that considers evasion as always unethical, while the smallest group considers evasion as ethical. It has been found that women are less prone to tax evasion and that older individuals are less likely to view evasion as ethic. Regarding the courses, it was noticed that the students of Accounting are less prone to tax evasion when compared to the students of the courses of Business Management and Economics. Finally, the views of each of the groups were synthesized through the analysis of the Discourse of the Collective Subject.

Keywords: Ethics; Tax Evasion; Business Field Students.

\section{RESUMEN}

La evasión fiscal es un problema conductual que amenaza la capacidad del gobierno para recaudar ingresos. Sin embargo, todavía son pocos los trabajos que examinan la no conformidad con las obligaciones tributarias bajo una mirada ética. En la literatura sobre el tema, surgieron tres visiones relacionadas a la ética de la evasión fiscal. La primera asume que la evasión nunca es ética. La segunda asume que la evasión es siempre o casi siempre ética. La tercera visión 

DE NEGÓCIOS?

está asociada a la noción de que la evasión no es absolutamente antiética. En este sentido, el presente trabajo tuvo por objetivo investigar cómo 195 estudiantes de los cursos de Administración, Ciencias Contables y Economía de Universidades Federales de Minas Gerais se posicionan en relación a esas tres visiones, partiendo del modelo de McGee, Ho y Li (2008), que presenta 15 afirmaciones sobre la evasión fiscal. Los estudiantes fueron clasificados de acuerdo con su visión a través de un análisis de cluster y se analizaron las asociaciones de variables como edad, sexo, etc. con cada uno de los grupos formados Después de la realización de un análisis de cluster, se constató que la mayoría de los estudiantes fueron colocados en el grupo que considera la evasión como siempre antiética, mientras que la menor parte considera la evasión como ética. Se constató que las mujeres son menos propensas a la evasión fiscal y que individuos de mayores franjas de edad son menos propensos a ver la evasión como ética. En relación a los cursos, se percibió que los alumnos de Ciencias Contables son menos propensos a la evasión fiscal en relación a los alumnos de los cursos de Administración y Ciencias Económicas. Por último, se sintetizaron las visiones de cada uno de los grupos por medio del análisis del Discurso del Sujeto Colectivo.

Palabras-clave: Ética; Evasión fiscal; Estudiantes del área de negócios.

\section{INTRODUÇÃO}

As obrigações tributárias são fontes de conflito e de insatisfação, pois parte da sociedade entende que os tributos pagos não são aplicados adequadamente, além de não retornarem em forma de benefícios (GRYZYBOVSKY; HAHN, 2006). Tais autores indicam que, no cenário brasileiro, a visão de que o retorno do governo para a sociedade é incondizente com os elevados tributos arrecadados e a existência de casos de corrupção governamental, aliados ao desejo de aumento dos lucros pessoais, incentivam a mentalidade de sonegação de impostos. Porém, nem mesmo em nações mais desenvolvidas em termos de serviços governamentais o cumprimento das normas é realizado plenamente (MCGEE; HO; LI, 2008).

Legisladores e cientistas sociais têm reconhecido que a evasão fiscal é um problema comportamental que ameaça a capacidade do governo de levantar receitas, sendo este um problema que transcende fronteiras culturais e políticas (WEIGEL; HESSING; ELFFERS, 1987). Além do problema de redução das receitas governamentais, que prejudica a capacidade do governo de quitar seus crescentes compromissos financeiros, a evasão fiscal também gera preocupações em relação aos padrões de conduta, pois pode-se argumentar que o comportamento evasivo terá um efeito depreciativo nestes (GROENLAND; VELDHOVEN, 1982).

Apesar das crescentes preocupações com a evasão fiscal, conforme indicam McGee, Ho e Li (2008), ainda são poucos os trabalhos que examinam a não-conformidade com as obrigações tributárias. De acordo com esses autores, a maior parte dos estudos que analisam a evasão fiscal foram conduzidos sob a perspectiva econômica ou de finanças públicas, sendo que poucos artigos discutiram a questão com base em um ponto de vista ético.

Analisando a evasão atrelada a questões éticas e demográficas, podem-se citar na literatura internacional, dentre outros trabalhos, os estudos de Eriksen e Fallan (1996), Tennyson (1997), McGee (2006), McGee e Ho (2006), McGee, Ho e Li (2008), Poço (2013) e Engida e Baisa (2014). Já na literatura brasileira cita-se o trabalho de Berger et al. (2009). Particular interesse nesses estudos é conferido aos estudantes de cursos da área de negócios (MCGEE; HO, 2006; MCGEE; HO; LI, 2008; BERGER et al., 2009), pois conforme indicam McGee e Ho (2006), estes terão importantes papéis na área de negócios e na área política.

McGee (2006) indica que uma revisão da literatura sobre a ética da evasão fiscal revela três principais pontos de vista que emergiram ao longo dos últimos anos. O primeiro toma a posição de que a evasão é sempre ou quase sempre antiética, por ser uma espécie de dever 
religioso ou devido ao senso de dever social. Outra visão é oposta, indicando que pagar impostos não deveria ser um dever, pois o governo sempre expropria os indivíduos. A terceira visão assume que, embora exista uma obrigação ética para se suportar o governo do país onde se mora, esse dever não é absoluto, sendo esta visão um meio termo das demais. Embora alguns estudos tenham analisado como profissionais e estudantes se posicionam quanto à evasão fiscal indicando quais fatores levam ao comportamento evasivo (POÇO, 2013; ERIKSEN; FALLAN, 1996; dentre outros), os trabalhos não trouxeram um exame direto de como estes se posicionam em relação a essas três visões.

Com base no exposto, o presente trabalho busca suprir essa lacuna na literatura, indagando: Como estudantes da área de negócios se posicionam em relação à ética na evasão fiscal? Tendo em vista a questão proposta, o objetivo principal deste trabalho foi identificar como estudantes de Universidades Federais mineiras de cursos da área de negócios (Administração, Ciências Contábeis e Ciências Econômicas) se posicionam em relação às três visões da literatura sobre ética e evasão fiscal. Como objetivos específicos, buscou-se: i) identificar qual das três visões sobre a evasão é mais disseminada entre os estudantes e; ii) identificar como diversos fatores estão associados a cada visão.

O estudo se justifica pela importância de se analisar a evasão fiscal sob um olhar ético, principalmente no cenário brasileiro, no qual há poucos trabalhos publicados sobre o tema. Os resultados do presente estudo contribuem para o entendimento das diferentes percepções sobre a ética da evasão fiscal ao identificar os discursos comuns apresentados por indivíduos pertencentes a grupos com diferentes visões sobre este tema, além de mostrar como indivíduos com diferentes características (curso, sexo, idade, tempo de curso etc) estão associados a esses grupos, sendo estes conhecimentos de particular interesse para educadores e construtores de políticas públicas.

\section{REFERENCIAL TEÓRICO}

\subsection{Noções Sobre Ética}

A palavra "ética" tem origem no grego ethos, que pode significar "modo de ser" ou "caráter", enquanto a palavra moral vem de mos ou moses, que indicam "costume" ou "costumes" (VÁSQUEZ, 2002). De acordo com Vásquez, o ethos e a mos originalmente se assentam em uma forma de comportamento que não corresponde a uma disposição natural do ser humano, sendo adquirido ou conquistado através do hábito. No entanto, o autor indica que essas definições não fornecem o atual significado dos dois termos, embora sejam eficientes para distinguir o que é adquirido ou conquistado pelo homem daquilo que é de sua natureza.

Em uma definição mais recente, Moreira (1999) indica que a ética como parte da filosofia é uma matéria que trata das avaliações do ser humano em relação às condutas dos indivíduos e às suas condutas sob o prisma do bem e do mal, de acordo com um critério ditado pela moral.

Nesse contexto, Vásquez (1995, p.23) afirma que "a ética é a teoria ou ciência do comportamento moral dos homens em sociedade. Ou seja, é ciência de uma forma específica de comportamento humano". Logo, não há de se falar em ética sem se falar na forma como se comportam os indivíduos. De forma complementar, para Deleuze (2002), a definição comum atual de ética, construída após a revolução industrial, é de que esta é a área da filosofia que busca explicar e justificar os costumes de um determinado grupo humano, bem como subsidiar a solução de seus frequentes dilemas.

Valls (1994) expõe que a ética, além de ser entendida tradicionalmente como um estudo científico ou filosófico, e eventualmente até teológico, sobre as ações e costumes humanos, também pode ser a realização de um determinado comportamento. Ele explica que as questões de ética aparecem a cada dia. Em um país capitalista, por exemplo, uma pessoa pode questionar 

DE NEGÓCIOS?

se o princípio do lucro poderia ou deveria situar-se acima ou abaixo das leis da ética. Em épocas mais difíceis, o autor alega que é comum que as pessoas se perguntem se uma lei injusta de um Estado autoritário precisa ou não ser obedecida.

Diante desses "problemas de consciência" que trazem um "sentimento de culpa" aos indivíduos, cabe à reflexão ética indagar se o homem pode realmente ser culpado ou se o desconforto em sua consciência é apenas um mal-estar sem fundamento (VALLS, 1994).

Diante dos conceitos expostos, pode-se inferir que a ética é uma ciência que estuda o comportamento humano a fim de indicar o melhor a ser adotado, visando o bem individual e coletivo. Este estudo pode ser feito através das avaliações dos indivíduos em relação às condutas humanas (MOREIRA, 1999), as quais podem divergir. Portanto, assim como outras questões que geram controvérsias, a percepção dos indivíduos em relação à evasão fiscal pode ser analisada dentro do contexto da ética. Os próximos tópicos do presente trabalho tratam, respectivamente, sobre a relação entre a evasão fiscal e a ética e, sobre as três visões que emergiram sobre esta relação na literatura.

\subsection{Evasão fiscal e Ética}

Berger et al. (2009) expõem que contribuintes em geral buscam reduzir a sua carga tributária. Os autores indicam que eles o fazem por meio lícito, que seria através de um planejamento tributário, também chamado de elisão fiscal, ou por meio ilícito, anulando ou reduzindo a carga tributária com a evasão fiscal.

A evasão fiscal, também conhecida como sonegação, é um problema antigo cuja ocorrência compromete o funcionamento da economia como um todo, na medida em que afeta a eficiência econômica, reduz a equidade tributária e prejudica as ações de política econômicotributária (SIQUEIRA; RAMOS, 2006). Dessa forma, conforme indicam Siqueira e Ramos (2006), o controle dos níveis de evasão fiscal deve se caracterizar como um dos principais objetivos das autoridades tributárias.

No Brasil, há uma grande predisposição ao não pagamento de impostos, uma vez que há um sentimento generalizado de que os valores arrecadados não são aplicados de forma eficiente pelo governo, o que contribui para um aumento do desejo de sonegar (SIQUEIRA; RAMOS, 2006). Uma investigação mundial sobre valores socioculturais e políticos, o World Value Survey, mostrou que os brasileiros apresentaram uma média de concordância em relação à sonegação de tributos superior a 49 dos 54 países em que a pesquisa foi feita, no período de 1995 a 1999 (BERGER et al., 2009).

A análise do comportamento predisposto à evasão fiscal, sob o prisma da ética, se caracteriza como pertinente na medida em que elucida as conexões entre variáveis culturais e essa predisposição. Exemplificando esta afirmativa, a pesquisa de McGee e Tyler (2006) revela que há diferença no grau de predisposição entre contribuintes de acordo com o país, gênero, idade, grau de instrução, religião e outros dados.

Em consonância, Poço (2013) argumenta serem as razões culturais e sociológicas que diferenciam apoio moral para o não cumprimento da obrigação fiscal. A autora analisou a percepção da população portuguesa em relação à evasão fiscal e identificou que as mulheres são menos propensas à sonegação do que os homens, que os mais velhos são mais avessos à evasão e que indivíduos do nível superior são menos propensos a evadir.

Segundo Poço (2013), os argumentos mais fortes para justificar a evasão fiscal estão relacionados com a corrupção entre os políticos, o desvio do dinheiro dos impostos, o sistema fiscal injusto, a carga tributária elevada e o desperdício ou má utilização do dinheiro arrecadado. Sua pesquisa concluiu que há menos oposição à evasão fiscal quando um governo é corrupto e opressivo ou quando o sistema tributário é considerado injusto. Por fim, a autora observou que o fato de as pessoas poderem vir a ser descobertas pelo fisco não foi um elemento dissuasor, encontrando-se entre os argumentos mais fracos. Nos estudos de Alligham e Sandmo (1972), 
este último elemento é considerado como o rendimento do tributo sonegado, como mostrado a seguir.

Alligham e Sandmo (1972) propuseram um modelo econômico destinado a explicar as razões de um contribuinte evadir ou não tributos. No modelo, o processo de tomada de decisão depende de variáveis como renda, risco de ser auditado e percentual da multa que o contribuinte terá se for descoberto. Supõe-se que o contribuinte racional considera a renda omitida como um ativo de risco. O rendimento desse ativo depende da possibilidade de ter a sua omissão detectada por uma auditoria e de sua punição. Com base nesses dados, decide-se pela maximização de uma função de utilidade esperada. Diferentemente dos estudos de McGee (MCGEE, 2006; MCGEE, HO e LI, 2008; dentre outros), o contribuinte é considerado alguém perfeitamente amoral, que toma decisões unicamente em função das consequências em sua renda líquida. Em contraste com o trabalho de Alligham e Sandmo (1972), Bordignon (1993) sugere um modelo no qual a noção de justiça ou equidade ajuda a explicar o comportamento dos indivíduos, que não seriam motivados apenas pela renda, mas também por outros valores. Este modelo é mais alinhado aos achados empíricos.

O trabalho empírico de McGee, Ho e Li (2008), por exemplo, realizado com estudantes de universidades de Hong Kong e dos Estados Unidos, todos da área de negócios, relatou que as diferenças quanto à adesão à evasão fiscal são resultado de razões culturais e sociológicas. Observou-se também, nessa pesquisa, pouco apoio moral para a evasão fiscal e concluiu-se que a oposição à evasão fiscal se enfraquece quando o governo é corrupto ou opressivo ou o sistema tributário é considerado injusto.

Outro fator interessante analisado em trabalhos empíricos é a profissão ou a formação. Comparando a visão de estudantes de contabilidade, administração e economia, McGee e Ho (2006) partiram da hipótese de que estudantes de contabilidade seriam menos propensos à evasão fiscal, encontrando resultados condizentes com esta hipótese. Entretanto, os autores indicam que o resultado pode ser explicado pelo fato de que estes não estão ainda exercendo a profissão, pois, na prática, os contadores seriam o grupo mais propenso a auxiliar clientes a evadir impostos.

Berger et al. (2009) realizaram uma pesquisa sobre a ética da evasão fiscal no cenário brasileiro. Foi aplicado um questionário adaptado de McGee e Smith (2006), com 18 afirmações, aos estudantes de administração, economia e contabilidade e profissionais da área de negócios, no estado do Espírito Santo. Como resultados da pesquisa, os autores apresentaram que as justificativas de maior aceitação para a evasão fiscal foram a má gestão do dinheiro dos impostos e a carga fiscal demasiado elevada. Além disso, os homens são mais propensos à evasão fiscal em comparação com as mulheres e as pessoas mais idosas são menos avessas à evasão que as mais jovens. Por fim, os autores também indicam que economistas apresentaram maior propensão à evasão em relação a indivíduos relacionados à área de administração, que, por sua vez, se mostraram mais permissivos que aqueles da área contábil.

Percebe-se que indivíduos apresentam diferentes visões sobre a relação entre ética e evasão fiscal de acordo com fatores como a educação, a religiosidade, a idade, dentre outros. No próximo tópico serão tratadas as três principais visões que emergiram na literatura sobre o tema.

\subsection{Três Visões Sobre a Ética na Evasão Fiscal}

Na primeira metade do século XX, Crowe (1944) escreveu uma tese de doutorado na qual traz um sumário elaborado com base na análise de 500 anos da literatura que debate a moral no pagamento de impostos. O autor encontra três visões nesta análise, discutidas a seguir: i) a evasão nunca é ética; ii) a evasão nunca é antiética e; iii) a evasão algumas vezes é ética. Ressalta-se que a literatura sobre essas visões após a publicação deste trabalho é ainda incipiente, entretanto, McGee (2006) traz uma extensa revisão sobre o tema. 

DE NEGÓCIOS?

A primeira linha de pensamento é a de que indivíduos possuem um dever de pagar o que quer que o Estado demande, não existindo a noção de que os tributos são muito altos, sendo esta visão justificada em uma democracia pela teoria do consentimento, pois parte-se da noção de que o papel de governo é desempenhado por especialistas (MCGEE, 2006). Essa visão é particularmente atrelada a uma moral religiosa (CROWE, 1944; COHN, 1998; MCGEE, 2006). Cohn (1998), por exemplo, mostra que a perspectiva judaica sobre o pagamento de tributos é aproximadamente absolutista, pois estes acreditam dever seguir as regras, tanto para realizarem boas ações para a comunidade quanto para não depreciarem a própria religião. Tamari (1998) apresenta resultados similares aos de Cohn (1998).

A segunda linha de pensamento é a de que nunca ou quase nunca há um dever de se pagar impostos, pois o governo sempre estaria expropriando a riqueza dos indivíduos e não é dever da população dar nada a um governo corrupto (MCGEE; HO, 2006). Bordignon (1993) indica que essa visão é disseminada na literatura econômica, que assume que os pagadores de tributos enxergam o pagamento ao Estado como coerção e que estes não o fariam se a chance de serem pegos fosse pequena. Porém, o problema dessa abordagem é que diverge do comportamento fiscal observado (BORDIGNON, 1993). McGee (2006) indica que, por falta de um melhor termo, rotula essa visão de visão anarquista. $\mathrm{O}$ autor indica que para os adeptos da visão, o governo seria um mero ladrão que confisca riquezas da sociedade sem o seu consentimento.

A terceira visão é uma espécie de misto entre as demais. Essa visão é a de que há alguma obrigação ética para que se pague tributos, porém, esta não seria absoluta (MCGEE; HO, 2006). Em certo sentido, essa visão indica que a evasão pode ser ética em algumas circunstâncias (MCGEE, 2006). Para McGee (2006), essa visão é a mais disseminada, porém, não há uma linha clara em relação a quando a evasão seria ética ou não.

Pode-se notar que as três visões observadas por Crowe (1944) sustentam-se em diferentes argumentações que justificam o nível de propensão à evasão fiscal. Isso mostra a importância da discussão a respeito da evasão fiscal sob o campo da ética, pois todas as posturas assumidas podem apresentar-se como mais aceitáveis para determinado indivíduo, considerando fatores como sua idade, sua formação educacional e familiar, dentre outros. Nesse contexto, a discussão sobre este tópico deve ser difundida, de forma a se beneficiar a sociedade como um todo.

\section{PROCEDIMENTOS METODOLÓGICOS}

O presente estudo tem como objetivo identificar como estudantes de Universidades Federais mineiras de cursos da área de negócios se posicionam em relação às três visões da literatura sobre ética e evasão fiscal. Nesse sentido sua classificação quanto aos objetivos é descritiva. Em relação à abordagem metodológica o trabalho pode ser classificado como qualiquantitativo, pois foram utilizadas técnicas estatísticas em conjunto com a análise do Discurso do Sujeito Coletivo (DSC). Segundo Lefèvre e Lefèvre (2006), a DSC apresenta como característica a dupla representatividade (quali e quanti) das opiniões coletivas analisadas.

Adaptou-se neste estudo o questionário de McGee, Ho e Li (2008) para o cenário brasileiro. O modelo destes autores apresenta 15 afirmações sobre o posicionamento de um indivíduo em relação à ética da evasão fiscal em diferentes cenários, em relação aos quais estes devem se posicionar em uma escala tipo likert de 7 pontos $(1=$ discordo plenamente; $7=$ concordo plenamente) na qual apenas foram denominados os valores extremos. Além disso, foram obtidas informações referentes à faixa etária dos indivíduos, ao seu sexo, ao estágio em que se encontram no curso, se estes já haviam cursado disciplinas da área tributária e, por fim, foi deixado um espaço de resposta não obrigatória para que estes expusessem sua visão sobre o tema, caso julgassem interessante. 
A amostra deste estudo é composta por 195 estudantes dos cursos de Administração, Ciências Contábeis e Ciências Econômicas de onze Universidades Federais situadas em Minas Gerais. Foram enviados $e$-mails aos coordenadores dos três cursos de diversas universidades solicitando que estes divulgassem o endereço eletrônico dos questionários aos discentes. Além disso, foi realizada a divulgação por meio de redes sociais online.

Após a obtenção das respostas, o estudo seguiu os seguintes passos: i) foi realizada uma análise de cluster pelo método não hierárquico $k$-means para, com base nas variáveis do questionário, classificar os respondentes quanto à sua visão sobre a evasão fiscal; ii) analisouse como diferentes características (sexo, curso, dentre outras) estavam associadas às diferentes visões e; iii) por meio da análise do DSC, foram sintetizadas as visões de cada grupo em relação à evasão fiscal, para confirmar a adequação teórica dos grupos gerados pela análise de cluster.

\subsection{Análise de Cluster: 0 método k-means}

A técnica multivariada de análise de cluster ou de agrupamentos tem como objetivo agregar objetos com base nas características que estes possuem (HAIR et al., 2009). A formação de clusters é o processo de partição ou agrupamento de um conjunto de observações em clusters com padrões distintos entre si e semelhantes dentre si (ALSABTI; RANKA; SINGH, 1997).

O primeiro passo na análise de cluster é o cálculo de uma medida de distância. No presente trabalho foi utilizada a distância euclidiana quadrada. A distância euclidiana quadrada é dada por:

\section{Distância Euclidiana Quadrada:}

$$
d_{i j}^{2}=\left(x_{1 i}-x_{1 j}\right)^{2}+\left(x_{2 i}-x_{2 j}\right)^{2}+\cdots+\left(x_{n i}-x_{n j}\right)^{2}
$$

$\mathrm{O}$ método $k$-means permite a divisão de $\mathrm{N}$ indivíduos em $\mathrm{K}$ classes, de forma que a distância euclidiana quadrada entre os objetos de um mesmo grupo e o seu centroide sejam ao menos tão pequenas quanto a sua distância para os centroides dos demais clusters, sendo o centroide o ponto médio entre os valores de cada variável dos objetos que se encontram em um mesmo grupo (STEINLEY, 2006).

No presente estudo, foram utilizadas as respostas às 15 questões do questionário baseadas em McGee, Ho e Li (2008) para gerar três grupos, os quais posteriormente foram associados a cada uma das visões sobre a evasão expostas. Após a formação dos grupos, analisou-se a associação de cada variável (sexo, curso etc.) com os grupos formados.

\subsection{Discurso do Sujeito Coletivo}

A estratégia do Discurso do Sujeito Coletivo (DSC) foi criada por Lefèvre, Lefèvre e Teixeira (2000) da Faculdade de Saúde Pública da Universidade de São Paulo. Na técnica de DSC se constrói um discurso coletivo munido de carácter social a partir das respostas dos entrevistados (MARTINS; THEÓPHILO, 2009). O conjunto dos discursos constitui as representações sociais, que são entidades sociais complexas que possuem função de guiar, orientar e justificar as ações cotidianas sobre algum tema. O conjunto dessas representações sociais forma o imaginário existente sobre dado tema.

$\mathrm{Na}$ modalidade de Discurso do Sujeito Coletivo, apresentam-se os resultados de pesquisas que têm como fonte depoimentos discursos, através de um ou mais discursos-síntese expostos no tempo verbal da primeira pessoa, na tentativa de expressar um pensamento coletivo (LEFÈVRE; CRESTANA; CORNETTA, 2003).

Lefèvre e Lefèvre (2006) indicam que a novidade de sua técnica é a dupla representatividade (quali e quanti) das opiniões coletivas analisadas. A representatividade 

DE NEGÓCIOS?

qualitativa advém dos discursos individuais, porém, a representatividade também é quantitativa, visto que esse discurso possui uma expressão numérica e, portanto, possui confiabilidade estatística quando se considera a sociedade como um coletivo de indivíduos.

Os autores complementam a discussão apresentando a noção das camadas discursivas, afirmando que as representações sociais expressas pelo Discurso do Sujeito Coletivo devem ser vistas como camadas sucessivas de discursos para se interpretar o pensamento da coletividade. No presente estudo, as três visões sobre a evasão (MCGEE, 2006) são exemplos de diferentes camadas. Para os construtores da referida metodologia, o que se busca fazer com a estratégia é "reconstruir, com pedaços de discursos individuais, como em um quebra-cabeças, tantos discursos-síntese quantos se julgue necessário para expressar uma dada "figura", ou seja, um dado pensar ou representação social sobre um fenômeno" (LEFÈVRE; LEFÈVRE; TEIXEIRA, 2000, p.19).

A construção do DSC se embasa em quatro fatores: ancoragem, ideia central, expressões-chave e o discurso do sujeito coletivo, todos importantes para a análise. Segundo Martins e Theóphilo (2009), a ancoragem engloba aspectos vinculados ao indivíduo que discursa, como conceitos, ideologias e traços linguísticos. Assim, Lefèvre, Lefèvre e Teixeira (2000) entendem que o discurso está ancorado quando é possível verificar traços linguísticos presentes na sociedade que estejam presentes no indivíduo.

Para Lefèvre, Lefèvre e Teixeira (2000), a ideia central pode ser entendida como afirmações capazes de traduzir o conteúdo discursivo exposto pelo sujeito em seus depoimentos. Os autores Martins e Theóphilo (2009) indicam que este é o aspecto principal do discurso. As expressões-chave são as partes dos depoimentos que servem de prova do entendimento dos aspectos mencionados acima (MARTINS; THEÓPHILO, 2009). Lefèvre, Lefèvre e Teixeira (2000), as caracterizam como uma prova discurso-empírica da veracidade das ideias centrais e das ancoragens.

O discurso do sujeito coletivo parte do fragmento de discursos individuais, buscando construir um discurso coletivo, como se fosse apenas um discurso (MARTINS; THEÓPHILO, 2009). Lefèvre, Lefèvre e Teixeira (2000, p. 20-21) apresentam as maneiras apropriadas de se construir um DSC. Deve-se iniciar pela organização dos depoimentos. Executada, basicamente, de duas formas:

\footnotetext{
A) Na primeira forma (Forma A), analisa-se cada depoimento e extraem-se, de cada um, as diferentes (mas complementares) ideias centrais e suas respectivas expressõeschave.

Em seguida, agregam-se ou "somam-se", as ideias centrais e/ou suas expressões chave para obter o DSC.

B) Na segunda forma (Forma B), analisa-se cada depoimento, extraindo-se as ideias centrais.

Em seguida identificam-se as ideias centrais iguais ou equivalentes e suas respectivas expressões-chave (LEFÈVRE; LEFÈVRE; TEIXEIRA, 2000, p. 20).
}

Quando o pesquisador considera que para representar a realidade estudada necessita-se decompô-la em ideias centrais, em si mesmas ricas e complexas, preferencialmente deve-se utilizar a Forma B (LEFÈVRE; LEFÈVRE; TEIXEIRA, 2000), sendo este o procedimento adotado no presente trabalho.

\section{RESULTADOS E DISCUSSÕES}

\subsection{Estatística Descritiva}

A amostra é composta por 88 mulheres $(45,13 \%)$ e 107 homens $(54,87 \%)$. Em relação aos cursos, 83 discentes estão cursando Ciências Econômicas (42,56\%), 60 estão cursando 
Felipe R. Cruz - Ana Clara V. Paiva - Jacqueline V. Alves da Cunha - João E. Barbosa Neto

Ciências Contábeis (30,77\%) e 52 estão cursando Administração (26,66\%). Na Tabela 1 expõese o número de indivíduos para cada faixa de idade.

Tabela 1: Estatística descritiva da faixa de idade dos estudantes

\begin{tabular}{ccc}
\hline Faixa de Idade & Número de Indivíduos & Percentual \\
\hline $16-20$ anos & 58 & $29,74 \%$ \\
$21-25$ anos & 99 & $50,77 \%$ \\
$26-30$ anos & 24 & $12,31 \%$ \\
$31-35$ anos & 10 & $5,13 \%$ \\
$36-40$ anos & 2 & $1,03 \%$ \\
41 anos ou mais & 2 & $1,03 \%$ \\
\hline
\end{tabular}

Fonte: Elaborada pelos autores com base nos dados da pesquisa.

Quanto ao estágio no curso dos entrevistados, 93 se encontravam na primeira metade $(47,18 \%)$ e $102(52,82 \%)$ na segunda metade. Quando indagados sobre se já cursaram disciplinas da área tributária (Contabilidade Tributária e Direito Tributário), 54 estudantes haviam cursado Contabilidade Tributária (27,69\%), 65 haviam cursado Direito Tributário (33,33\%), 44 haviam cursado ambas (22,56\%). Ademais, 120 não haviam cursado nenhuma das duas $(61,54 \%)$ e 75 haviam cursado ao menos uma $(38,46 \%)$. Na Tabela 2 é exposta a média das respostas entre 1 e 7 dos respondentes em relação às quinze afirmações elaboradas com base em McGee, Ho e Li (2008).

Tabela 2: Sumário das respostas sobre ética e evasão para toda a amostra*

\begin{tabular}{|c|c|c|}
\hline Afirmação & Média & $\begin{array}{c}\text { Desvio } \\
\text { Padrão } \\
\end{array}$ \\
\hline 1 - A evasão fiscal é ética se a carga tributária é muito alta. & 2.5128205 & 1.946074 \\
\hline $\begin{array}{l}2 \text { - A evasão fiscal é ética mesmo se a carga tributária não for tão alta, pois o } \\
\text { governo não possui o direito de tomar de mim tanto quanto toma. }\end{array}$ & 2.1538462 & 1.84081 \\
\hline $\begin{array}{l}3 \text { - A evasão fiscal é ética se o sistema tributário é injusto. } \\
4 \text { - A evasão fiscal é ética se uma grande parte do dinheiro coletado é } \\
\text { desperdiçada. }\end{array}$ & 3.0820513 & 2.171378 \\
\hline $\begin{array}{l}5 \text { - A evasão fiscal é ética mesmo se a maior parte do dinheiro coletado for } \\
\text { gasta de forma sensata. }\end{array}$ & 2.1128205 & 1.818459 \\
\hline $\begin{array}{l}6 \text { - A evasão fiscal é ética se uma grande parte do dinheiro arrecadado é gasta } \\
\text { em projetos que desaprovo moralmente. }\end{array}$ & 2.4820513 & 1.951324 \\
\hline $\begin{array}{l}7 \text { - A evasão fiscal é ética mesmo se uma grande parte do dinheiro arrecadado } \\
\text { for gasta em projetos dignos. }\end{array}$ & 2.0974359 & 1.843278 \\
\hline $\begin{array}{l}8 \text { - A evasão fiscal é ética se uma grande parte do dinheiro arrecadado for } \\
\text { gasta em projetos que não me beneficiam. }\end{array}$ & 2.1384615 & 1.806719 \\
\hline $\begin{array}{l}9 \text { - A evasão fiscal é ética mesmo se grande parte do dinheiro arrecadado for } \\
\text { gasta em projetos que me beneficiam. }\end{array}$ & 2.0205128 & 1.749695 \\
\hline 10 - A Evasão fiscal é ética se todos a estiverem praticando. & 2.0717949 & 1.851434 \\
\hline $\begin{array}{l}11 \text { - A evasão fiscal é ética se uma parte significativa do dinheiro arrecadado } \\
\text { acabar nos bolsos de políticos corruptos ou de seus amigos e familiares. }\end{array}$ & 2.9230769 & 2.208052 \\
\hline 12 - A evasão fiscal é ética se a probabilidade de ser pego for pequena. & 1.7589744 & 1.582234 \\
\hline $\begin{array}{l}13 \text { - A evasão fiscal é ética se parte da arrecadação for destinada a apoiar uma } \\
\text { guerra que considero ser injusta. }\end{array}$ & 2.7794872 & 2.095058 \\
\hline 14 - A evasão fiscal é ética se eu não puder pagar. & 3.1948718 & 2.173641 \\
\hline $\begin{array}{l}15 \text { - A evasão fiscal é ética mesmo que isso signifique que se eu pagar menos, } \\
\text { outros terão de pagar mais. }\end{array}$ & 1.9897436 & 1.729042 \\
\hline
\end{tabular}

*1 - Discordo Plenamente; 7 Concordo Plenamente

Fonte: Elaborada pelos autores com base nos dados da pesquisa. 

DE NEGÓCIOS?

De forma geral, percebe-se que as médias são menores que 3, indicando que, em geral, os estudantes da amostra são avessos à evasão fiscal. Os menores valores de concordância relacionam-se à propensão para a evasão quando há baixa possibilidade de que o ato ilícito seja observado (afirmação 12), além da possibilidade de que a evasão, se cometida, prejudique outros indivíduos (afirmação 15).

Apesar dos baixos valores observados para as questões, em relação às declarações 1 (a evasão fiscal é ética se a carga tributária é muito alta), 3 (a evasão fiscal é ética se o sistema tributário é injusto), 4 (a evasão fiscal é ética se uma grande parte do dinheiro coletado é desperdiçada), 6 (a evasão fiscal é ética se uma grande parte do dinheiro arrecadado é gasta em projetos que desaprovo moralmente), 11 (a evasão fiscal é ética se uma parte significativa do dinheiro arrecadado acabar nos bolsos de políticos corruptos ou de seus amigos e familiares), 13 (a evasão fiscal é ética se parte da arrecadação for destinada a apoiar uma guerra que considero ser injusta) e 14 (A evasão fiscal é ética se eu não puder pagar), as médias se apresentam um pouco mais elevadas, sendo estas questões relacionadas à justiça do sistema tributário e à corrupção dos políticos.

Estes resultados entram em consonância com os resultados de Poço (2013), que indicam que os argumentos mais fortes para justificar a evasão se relacionam à corrupção, à injustiça do sistema tributário e à má utilização dos recursos. Também em consonância com os resultados da autora, a improbabilidade de ser pego no ato de evasão é um argumento considerado fraco. Os resultados do presente estudo também se assemelham aos de Berger et al. (2009).

Tabela 3: Sumário das respostas sobre ética e evasão para cada grupo*

\begin{tabular}{|c|c|c|c|}
\hline Afirmação & $\begin{array}{l}\text { Média } \\
\text { Cluster } 1\end{array}$ & $\begin{array}{l}\text { Média } \\
\text { Cluster } 2\end{array}$ & $\begin{array}{c}\text { Média } \\
\text { Cluster } 3\end{array}$ \\
\hline 1 - A evasão fiscal é ética se a carga tributária é muito alta. & 6.36 & 3.20 & 1.31 \\
\hline $\begin{array}{l}2 \text { - A evasão fiscal é ética mesmo se a carga tributária não for tão } \\
\text { alta, pois o governo não possui o direito de tomar de mim tanto } \\
\text { quanto toma. }\end{array}$ & 5.86 & 2.42 & 1.24 \\
\hline 3 - A evasão fiscal é ética se o sistema tributário é injusto. & 6.59 & 4.34 & 1.61 \\
\hline $\begin{array}{l}4 \text { - A evasão fiscal é ética se uma grande parte do dinheiro coletado } \\
\text { é desperdiçada. }\end{array}$ & 6.50 & 3.94 & 1.50 \\
\hline $\begin{array}{l}5 \text { - A evasão fiscal é ética mesmo se a maior parte do dinheiro } \\
\text { coletado for gasta de forma sensata. }\end{array}$ & 5.64 & 2.55 & 1.13 \\
\hline $\begin{array}{l}6 \text { - A evasão fiscal é ética se uma grande parte do dinheiro } \\
\text { arrecadado é gasta em projetos que desaprovo moralmente. }\end{array}$ & 6.00 & 2.97 & 1.47 \\
\hline $\begin{array}{l}7 \text { - A evasão fiscal é ética mesmo se uma grande parte do dinheiro } \\
\text { arrecadado for gasta em projetos dignos. }\end{array}$ & 5.23 & 2.65 & 1.13 \\
\hline $\begin{array}{l}8 \text { - A evasão fiscal é ética se uma grande parte do dinheiro } \\
\text { arrecadado for gasta em projetos que não me beneficiam. }\end{array}$ & 5.55 & 2.65 & 1.14 \\
\hline $\begin{array}{l}9 \text { - A evasão fiscal é ética mesmo se grande parte do dinheiro } \\
\text { arrecadado for gasta em projetos que me beneficiam. }\end{array}$ & 5.09 & 2.43 & 1.15 \\
\hline 10 - A Evasão fiscal é ética se todos a estiverem praticando. & 4.18 & 2.77 & 1.22 \\
\hline $\begin{array}{l}11 \text { - A evasão fiscal é ética se uma parte significativa do dinheiro } \\
\text { arrecadado acabar nos bolsos de políticos corruptos ou de seus } \\
\text { amigos e familiares. }\end{array}$ & 6.09 & 4.14 & 1.55 \\
\hline $\begin{array}{l}12 \text { - A evasão fiscal é ética se a probabilidade de ser pego for } \\
\text { pequena. }\end{array}$ & 4.77 & 1.91 & 1.06 \\
\hline $\begin{array}{l}13 \text { - A evasão fiscal é ética se parte da arrecadação for destinada a } \\
\text { apoiar uma guerra que considero ser injusta. }\end{array}$ & 5.82 & 3.62 & 1.66 \\
\hline 14 - A evasão fiscal é ética se eu não puder pagar. & 6.23 & 4.32 & 1.90 \\
\hline $\begin{array}{l}15 \text { - A evasão fiscal é ética mesmo que isso signifique que se eu } \\
\text { pagar menos, outros terão de pagar mais. }\end{array}$ & 5.14 & 2.42 & 1.09 \\
\hline
\end{tabular}

* 1 - Discordo Plenamente; 7 Concordo Plenanente.

Fonte: Elaborada pelos autores com base nos dados da pesquisa. 
Felipe R. Cruz - Ana Clara V. Paiva - Jacqueline V. Alves da Cunha - João E. Barbosa Neto

Os resultados, embora aparentem indicar que a visão destes estudantes é predominantemente de aversão à evasão, são influenciados por valores discrepantes e não permitem a associação de fatores específicos a cada uma das visões apresentadas. Logo, procedeu-se à realização da análise de cluster para identificar qual a visão mais disseminada.

\subsection{Análise de Cluster: Três Visões Sobre Evasão Fiscal}

Após a realização da análise de cluster foram gerados três grupos. As médias dos grupos em relação a cada afirmação são expostas na Tabela 3. A partir das médias obtidas para cada um dos grupos, estes foram associados às três visões sobre a ética da evasão fiscal apontadas por Crowe (1944).

Após a análise das médias de cada grupo para as afirmativas sobre a ética da sonegação, o primeiro cluster foi associado à visão de que a evasão fiscal sempre é ética. O segundo foi associado à visão de que as obrigações fiscais não são absolutas. O terceiro foi associado à visão de que a evasão fiscal nunca ou quase nunca é ética. O primeiro grupo apresentou 22 indivíduos $(11,28 \%)$, o segundo apresentou 65 indivíduos $(33,33 \%)$ e o terceiro apresentou 108 indivíduos $(55,38 \%)$. Logo, percebe-se que a maioria dos estudantes acredita que a evasão é nunca (ou quase nunca) ética.

Com base na classificação dos indivíduos em relação aos clusters, foi analisado como as características dos indivíduos estavam associadas a cada grupo. Na tabela 4 expõe-se a associação de homens e mulheres às diferentes visões.

Tabela 4: Associação do Gênero com as Três Visões Sobre a Evasão

\begin{tabular}{lccccc} 
& Sexo & Grupo 1 & Grupo 2 & Grupo 3 & Total \\
\hline Feminino & & $6.82 \%$ & $34.09 \%$ & $59.09 \%$ & $100.00 \%$ \\
Masculino & $14.95 \%$ & $32.71 \%$ & $52.34 \%$ & $100.00 \%$ \\
\hline
\end{tabular}

Fonte: Elaborada pelos autores com base nos dados da pesquisa.

Por meio da Tabela 4 é possível observar que, em média, indivíduos do sexo feminino são mais associados ao grupo 3 do que os do sexo masculino, indicando que as mulheres são menos propensas à evasão fiscal. Berger et al. (2009) obtiveram resultados semelhantes para uma amostra de profissionais e estudantes da área de negócios do Estado do Espírito Santo. Estes achados também se assemelham aos de Poço (2013).

Tabela 5: Associação dos Cursos com as Três Visões Sobre a Evasão

\begin{tabular}{lcccc}
\hline \multicolumn{1}{c}{ Curso } & Grupo 1 & Grupo 2 & Grupo 3 & Total \\
\hline Administração & $11.54 \%$ & $36.54 \%$ & $51.92 \%$ & $100.00 \%$ \\
Ciências Contábeis & $10.00 \%$ & $25.00 \%$ & $65.00 \%$ & $100.00 \%$ \\
Ciências Econômicas & $12.05 \%$ & $37.35 \%$ & $50.60 \%$ & $100.00 \%$ \\
\hline
\end{tabular}

Fonte: Elaborada pelos autores com base nos dados da pesquisa.

Em geral, os estudantes de Administração e Ciências Econômicas apresentaram percentuais de classificação em cada grupo bastante semelhantes. Em contraste com os estudantes de Ciências Contábeis, os alunos dos primeiros cursos se apresentaram mais propensos à evasão fiscal, sendo este resultado semelhante aos de McGee e Ho (2006) e Berger et al. (2009), que também compararam a visão de estudantes dos três cursos. Porém, conforme afirmam McGee e Ho (2006), o resultado poderia não ser semelhante para profissionais da área contábil, pois pode existir uma divergência entre a prática e a fase de estudos.

Outra questão importante a se avaliar é se alunos em diferentes estágios de seus respectivos cursos apresentam diferentes visões sobre a ética da evasão físcal. Na Tabela 6 é exposto como alunos em diferentes estágios do curso se posicionam em relação à evasão fiscal. 
TRÊS VISÕES SOBRE ÉTICA E EVASÃO FISCAL: COMO SE POSICIONAM OS ESTUDANTES DA ÁREA DE NEGÓCIOS?

Tabela 6: Associação do Estágio do Curso e das disciplinas cursadas com as Três Visões Sobre Ética e Evasão Fiscal

\begin{tabular}{lcccc}
\hline \multicolumn{1}{c}{ Etapa do Curso } & Grupo 1 & Grupo 2 & Grupo 3 & Total \\
\hline Primeira Metade & $11.54 \%$ & $36.54 \%$ & $51.92 \%$ & $100.00 \%$ \\
Segunda Metade & $10.00 \%$ & $25.00 \%$ & $65.00 \%$ & $100.00 \%$ \\
\hline
\end{tabular}

Fonte: Elaborada pelos autores com base nos dados da pesquisa.

Os resultados expostos na Tabela 6 mostram que os alunos na segunda metade do curso são menos propensos à evasão fiscal, indicando que o maior nível de conhecimento pode ter relação negativa com a propensão à evasão. Esse resultado se alinha aos achados de Poço (2013) de que a conclusão do Ensino Superior diminui a propensão à evasão fiscal. Como forma de investigar se essa relação pode ser explicada por um maior conhecimento do sistema tributário, na Tabela 7 expõe-se a proporção de estudantes que cursaram (ou não cursaram) disciplinas da área tributária pertencentes a cada um dos clusters.

Tabela 7: Associação das Disciplinas de Contabilidade Tributária e Direito Tributário com as Três Visões Sobre Ética e Evasão Fiscal

\begin{tabular}{lcccc}
\hline \multicolumn{1}{c}{ Disciplinas Cursadas } & Grupo 1 & Grupo 2 & Grupo 3 & Total \\
\hline Cursou as duas & $13.64 \%$ & $27.27 \%$ & $59.09 \%$ & $100.00 \%$ \\
Cursou ao menos uma & $10.67 \%$ & $29.33 \%$ & $60.00 \%$ & $100.00 \%$ \\
Não cursou nenhuma. & $11.67 \%$ & $35.83 \%$ & $52.50 \%$ & $100.00 \%$ \\
\hline
\end{tabular}

Fonte: Elaborada pelos autores com base nos dados da pesquisa.

Em consonância com o exposto sobre a associação entre educação e a visão de que a evasão é antiética, por meio da Tabela 7 verifica-se que os alunos que cursaram Contabilidade Tributária e/ou Direito Tributário apresentam maior associação com o grupo 3, referente à visão de que a evasão nunca é ética. Entretanto, é interessante notar que os alunos que cursaram ambas as disciplinas são menos associados ao grupo 2, indicando que apresentam maior tendência a se posicionar nos extremos em relação ao grau em que concordam com a ética da evasão fiscal quando comparados aos demais alunos.

Por fim, é evidenciada na Tabela 8 a associação entre a idade dos indivíduos e as visões sobre evasão e ética. Devido ao baixo número de respostas para as faixas de idade de 36 a 40 anos e de 41 ou mais, estes indivíduos não foram analisados.

Tabela 8: Associação das Faixas de Idade com as Três Visões Sobre Ética e Evasão Fiscal.

\begin{tabular}{|c|c|c|c|c|}
\hline Faixa de Idade & Grupo 1 & Grupo 2 & Grupo 3 & Total \\
\hline $31-35$ & $10.00 \%$ & $10.00 \%$ & $80.00 \%$ & $100.00 \%$ \\
\hline $26-30$ & $8.33 \%$ & $33.33 \%$ & $58.33 \%$ & $100.00 \%$ \\
\hline $21-25$ & $11.11 \%$ & $33.33 \%$ & $55.56 \%$ & $100.00 \%$ \\
\hline $16-20$ & $13.79 \%$ & $34.48 \%$ & $51.72 \%$ & $100.00 \%$ \\
\hline
\end{tabular}

Fonte: Elaborada pelos autores com base nos dados da pesquisa.

Os dados da Tabela 8 demostram que, quanto mais velhos são os discentes, maior a probabilidade de estarem associados ao grupo 3, indicando que estudantes da área de negócio mais velhos são menos propensos à evasão. Em consonância, indivíduos da faixa de 16 a 20 anos se apresentaram mais propensos a acreditar que a evasão é ética.

Berger et al. (2009) obteve resultados contrastantes, indicando que as pessoas mais velhas apresentam menor aversão à evasão fiscal do que as mais jovens. Porém, este resultado pode ser explicado pela diferente amostra, visto que no presente estudo focou-se apenas em estudantes de Universidades Federais mineiras. Ademais, os autores também entrevistaram 
estudantes e profissionais da área de direito e realizaram seu estudo em outro Estado. Apesar dos resultados de Berger et al. (2009) contrastarem com os do presente estudo, Poço (2013) obteve resultados semelhantes, indicando que à medida que as pessoas envelhecem, se tornam mais avessas à evasão.

Para fornecer maiores insights sobre a visão de cada grupo, na próxima seção são expostos os resultados de uma Análise do Discurso do Sujeito Coletivo, por meio da qual são construídos discursos em primeira pessoa representativos da visão de cada um dos clusters formados.

\title{
4.3 Discurso do Sujeito Coletivo
}

Com base nas respostas não obrigatórias enviadas por indivíduos classificados em cada um dos clusters foi gerado um discurso para cada visão. Para o cluster número um - o menor , associado à visão de que a evasão é sempre ou quase sempre ética, o seguinte discurso foi construído com base nas respostas:

o poder de tributar do Estado é uma imposição negativa sobre a sociedade, visto que o Estado é ineficiente na gestão dos recursos, pautada em uma burocracia ineficaz. Não há retorno em bens e serviços para a sociedade proporcional à quantidade exacerbada de tributos recolhida aos cofres públicos. Além disso, não há a possibilidade de decidir sobre o pagamento do tributo, ele é obrigatório, configurandose, assim, como uma coerção. Dessa forma, a evasão fiscal é uma maneira legítima de se defender de um Estado corrupto e ineficaz. Imposto é roubo. Sonegar é legítima defesa. Estado é crime organizado. Bem estar público é falácia (DSC do grupo 1).

O discurso deste grupo tem como expressões-chave "Sonegar é legítima defesa", "Imposto é roubo", dentre outras expressões que levam à confirmação de que este grupo se aproxima ao que McGee (2006) nomeia de grupo anarquista. Em relação ao segundo grupo, associado à visão de que não há um dever absoluto de que se paguem tributos, foi construído o seguinte discurso:

\begin{abstract}
a tributação é extremamente necessária para que o Estado possa oferecer bens e serviços de qualidade aos cidadãos. Dessa forma, se o Estado for eficiente e eficaz, a evasão fiscal é inadmissível. O problema é que o Estado tem se mostrado ineficiente na gestão dos recursos arrecadados, não atingindo o objetivo da arrecadação dos tributos. Nesse caso, a evasão fiscal se justifica. Outro motivo que justifica a evasão fiscal é se a carga tributária é extremamente onerosa, fazendo com que o empreendedor, ao cumprir com a obrigação total, seja prejudicado, vindo à falência em muitos casos (DSC do grupo 2).
\end{abstract}

O segundo grupo, que engloba um terço dos entrevistados, apresenta como expressõeschave de seu discurso: "alta carga tributária", "é impossível arcar com a obrigação total", "Ineficiência do Estado", Impostos abusivos" e "O empreendedorismo não sobrevive". Percebe-se que estes dizeres se alinham com a noção de que não é absoluta a falta de ética na evasão, pois em alguns casos as ações estatais a justifica. Logo, este grupo se alinha com a visão de que embora exista uma obrigação ética para que se pague tributos esta não é absoluta (MCGEE; HO, 2006).

O terceiro grupo ou terceira camada é o mais representativo da visão dos estudantes que responderam ao questionário, englobando $55,38 \%$ dos respondentes. Sob a ótica deste grupo, a evasão fiscal nunca ou quase nunca é considerada como ética. O discurso criado com base nas respostas dos indivíduos classificados neste grupo é exposto a seguir: 

DE NEGÓCIOS?

\begin{abstract}
obrigação fiscal é prejudicar o coletivo. O descontentamento com a gestão pública da arrecadação e aplicação dos tributos deve levar a sociedade a fiscalizar melhor a ação do Estado, atentar mais ao voto e lutar por mudanças no sistema de arrecadação e aplicação dos tributos, através de vias legais. O fato do Estado ser ineficiente não justifica que os contribuintes também não cumpram com suas obrigações. O que deve ser feito é renovar os políticos que gerenciam o Estado. Evasão fiscal é crime. A saída é a elisão fiscal. Reforma tributária. Participação efetiva da sociedade civil. Sociedade organizada. Ilegalidade não é ética. Nada justifica a evasão (DSC do grupo 3).
\end{abstract}

Este grupo se mostra mais preocupado com o coletivo, indicando que a evasão prejudica a sociedade e, por isso, não deve ser considerada ética. Essa visão se alinha com a noção de que existe um dever comunitário (MCGEE, 2006). As expressões-chave deste grupo são "a evasão fiscal nunca é ética", "nada justifica a evasão" etc.

Percebe-se que os três grupos apresentam uma visão distinta sobre a evasão, apresentando uma lógica subjacente à posição tomada. Não necessariamente um grupo pode ser categorizado como antiético, pois simplesmente deve-se considerar que existem diferentes noções quando se discute sobre moralidade e ética. Ademais, deve-se perceber que os indivíduos possuem diferentes formações, experiências, influências sociais etc.

\title{
5 CONCLUSÃO
}

O presente trabalho utilizou um questionário baseado no modelo de McGee, Ho e Li (2008) que contém 15 afirmações sobre a ética e a evasão fiscal para analisar o posicionamento de estudantes de Universidades Federais mineiras de cursos da área de negócios em relação à evasão fiscal.

A análise da amostra completa revela que, de forma geral, os estudantes são avessos à evasão fiscal. Contudo, a resistência à sonegação se enfraquece quando o argumento se refere à corrupção dos políticos, à injustiça do sistema tributário e à má utilização dos recursos, revelando que, nesse contexto, a evasão fiscal se justificaria. Tal constatação está de acordo com os resultados encontrados na literatura. Outro fato constatado é o de que a não probabilidade de ser pego no ato de evasão não foi um argumento persuasivo para a visão de que a sonegação fiscal é ética.

Após a realização de uma análise de cluster constatou-se que a maioria dos estudantes posicionou-se no grupo que considera a evasão como sempre antiética, enquanto a menor parte considera a evasão como ética. Constatou-se que as mulheres são menos propensas à evasão fiscal e que a idade é inversamente relacionada com a propensão à aceitação da evasão fiscal, ou seja, que indivíduos de maiores faixas de idade são menos propensos a enxergar a evasão como ética.

Em relação aos cursos, percebeu-se que os alunos de Ciências Contábeis são menos propensos à evasão fiscal em relação aos alunos dos cursos de Administração e Ciências Econômicas. Ademais, verificou-se que a maior proximidade em relação à conclusão do curso pode diminuir a propensão à evasão fiscal, assim como o fato de os alunos terem cursado as disciplinas de Contabilidade Tributária e de Direito Tributário, sendo estes achados indicativos de que o nível de educação reduz a propensão à evasão fiscal.

Esses resultados podem ser relevantes para os elaboradores de políticas públicas, pois revelam que um maior nível educacional pode estar atrelado a menores níveis de propensão à sonegação de impostos. Visto que uma menor propensão à sonegação pode levar o governo a arrecadar mais receitas, esses resultados podem incentivar investimentos em educação. Com a finalidade de diminuir a propensão à evasão fiscal, o governo pode fazer investimentos com ênfase no ensino de disciplinas da área tributária.

Por fim, por meio da análise dos Discursos do Sujeito Coletivo elaborados para cada um dos grupos, foi possível a identificação do posicionamento coletivo dos indivíduos de em cada 
cluster e a confirmação do alinhamento teórico dos grupos, o que mostra que a técnica é uma forma para que se analisem as visões de diferentes camadas de pensamento e que esta pode ser atrelada à análise de clusters para tanto.

Através dos discursos elaborados, foi possível identificar que os três grupos apresentam argumentos coerentes que justificam suas visões. Isso revela que a aceitação ou não aceitação da evasão fiscal não está necessariamente atrelada à falta ou à presença de ética, mas sim a uma diferente visão do papel do Estado e dos tributos na sociedade. Esse entendimento deve ser considerado em novos estudos, pois não se pode partir da premissa de que a evasão físcal é uma prática antiética pelo fato de que a maior parcela dos indivíduos não a aceita. O estudo de uma prática sob o olhar da ética não reside apenas em avaliar o que é aceito pela maioria, mas também na discussão e na apresentação de argumentos coerentes sobre quais são as melhores condutas.

Ressalta-se que os resultados do presente estudo devem ser analisados considerando-se as limitações da pesquisa. A principal limitação do trabalho encontra-se na utilização de uma amostra reduzida. Outro fator que limita a generalização dos resultados é a composição da amostra apenas por estudantes de universidades federais do estado de Minas Gerais. Ademais, o presente trabalho não identificou como os aspectos culturais, financeiros e religiosos dos participantes os distinguem em relação a suas visões sobre a ética da evasão fiscal.

Sugere-se que novos trabalhos busquem analisar a evasão fiscal no cenário brasileiro sob um ponto de vista ético e que auxiliem na generalização dos resultados obtidos para o cenário brasileiro, podendo também ampliar os fatores associados à evasão. A religião dos respondentes, por exemplo, é um fator comumente analisado na literatura internacional. Ademais, trabalhos futuros podem comparar a visão de estudantes de contabilidade com profissionais da área contábil, buscando identificar se a proposição de McGee e Ho (2006) de que a visão apresentada pelos alunos do curso destoa do que os profissionais da área praticam é válida.

\section{REFERÊNCIAS}

ALLINGHAM, M. G.; SANDMO, A. Income tax evasion: a theoretical analysis. Journal of Public Economics, v. 1, n. 3-4, p. 323-338, 1972.

ALSABTI, K.; RANKA, S.; SINGH, V. An efficient k-means clustering algorithm. Electrical Engineering and Computer Science, 1997. Disponível em: http://surface.syr.edu/eecs/43/. Acesso em: 20 de dez. de 2016.

BERGER, F. S.; DALLAPICULA, T. M.; ALENCAR, R. C.; DALMÁCIO, F. Z. A ética da evasão fiscal: um estudo comparativo de profissionais e estudantes da área de negócios. In: International Accounting Congress - IAAER \& ANPCONT, 3, 2009. Anais... São Paulo: IAAER \& ANPCONT, 2009.

BORDIGNON, M. A fairness approach to income tax evasion. Journal of Public Economics, v. 52, n. 3, p. 345-362, 1993.

COHN, G. The Jewish view on paying taxes. Journal of Accounting, Ethics \& Public Policy, v. 1, n. 2, p. 109-120, 1998.

CROWE, M. T. The moral obligation of paying just taxes. Washington: Catholic University of America Press, 1944. 
TRÊS VISÕES SOBRE ÉTICA E EVASÃO FISCAL: COMO SE POSICIONAM OS ESTUDANTES DA ÁREA DE NEGÓCIOS?

DELEUZE, G. Filosofia prática. São Paulo: Escuta, 2002.

ENGIDA, T. G.; BAISA, G. A. Factors influencing taxpayers' compliance with the tax system: an empirical study in Mekelle City, Ethiopia. eJournal of Tax Research, v. 12, n. 2, p. 433-452, 2014.

ERIKSEN, K.; FALLAN, L. Tax knowledge and attitudes towards taxation: a report on a quasi-experiment. Journal of Economic Psychology, v.17, n. 3, p. 387-402, 1996.

GROENLAND, E. A.; VELDHOVEN, G. M. V. Tax evasion behavior: a psychological framework. Journal of Economic Psychology, v. 3, n. 2, p. 129-144, 1983.

GRZYBOVSKI, D.; HAHN, T. Educação fiscal: premissa para melhor percepção da questão tributária. Revista de Administração Pública (RAP), Rio de Janeiro, v. 40, n. 5, p. 841-864, 2006.

HAIR, J. F.; BLACK, W. C.; BABIN, B. J.; ANDERSON, B. E.; TATHAM, R. L. Análise Multivariada de Dados. 6 ed. Porto Alegre: Bookman, 2009.

LEFÈVRE, A. M. C.; CRESTANA, M. F.; CORNETTA, V. K. A utilização da metodologia do discurso do sujeito coletivo na avaliação qualitativa dos cursos de especialização" Capacitação e Desenvolvimento de Recursos Humanos em Saúde-CADRHU", São Paulo2002. Saúde e Sociedade, São Paulo, v. 12, n.2, p. 68-75, jul./dez., 2003.

LEFÈVRE, F.; LEFÈVRE, A. M. C.; TEIXEIRA, J. J. V. O discurso do sujeito coletivo: uma nova abordagem metodológica em pesquisa qualitativa. Caxias do Sul: EDUCS, 2000.

LEFÈVRE, F.; LEFÈVRE, A. M. C. O sujeito coletivo que fala. Interface-Comunic, Saúde, Educ, Botucatu-SP, v. 10, n. 20, p. 517-24, jul./dez., 2006.

MARTINS, G. de A; THEÓPHILO, C. R. Metodologia da investigação científica para ciências sociais aplicadas. 2 ed. São Paulo: Atlas. 2009.

MCGEE, R. W. Three views on the ethics of tax evasion. Journal of Business Ethics, v. 67, n. 1, p. 15-35, 2006.

MCGEE, R. W.; SMITH, S. R. Ethics and tax evasion: a comparative study of accounting and business student opinion in Utah. Andreas School of Business Working Paper, 2006. Disponível em <https://papers.ssrn.com/sol3/papers.cfm?abstract_id=941510 >. Acesso em: 13 de dez. de 2018.

MCGEE, R. W.; HO, S. S. The ethics of tax evasion: a survey of accounting, business and economics students in Hong Kong. Social Science Research Network (SSRN), p. 1-19, fev., 2006.

MCGEE, R. W.; TYLER, M. Tax evasion and ethics: a demographic study of 33 countries. Social Science Research Network (SSRN), p. 1-20. 2006.

MCGEE, R. W., HO, S. S.; LI, A. Y. A comparative study on perceived ethics of tax evasion: Hong Kong vs the United States. Journal of Business Ethics, v. 77, n. 2, p. 147-158, 2008. 
MOREIRA, J. M. A ética empresarial no Brasil. São Paulo: Pioneira, 1999.

POÇO, M. L. C. Percepção da evasão e fraude fiscal em Portugal: um estudo sociológico. 2013. 93 f. Dissertação (Mestrado em Contabilidade e Fiscalidade Empresarial) - Instituto Superior de Contabilidade e Administração de Coimbra, Instituto Politécnico de Coimbra. Coimbra, 2013.

SIQUEIRA, M. L.; RAMOS, F. S. Evasão fiscal do imposto sobre a renda: uma análise do comportamento do contribuinte ante o sistema impositivo brasileiro. Economia Aplicada, v. 10, n. 3, p. 399-424, 2006.

STEINLEY, D. K-means clustering: a half-century synthesis. British Journal of Mathematical and Statistical Psychology, v. 59, n. 1, p 1-34. 2006.

TAMARI, M. Ethical issues in tax evasion: a Jewish perspective. Journal of Accounting, Ethics \& Public Policy, v. 1, n. 2, p. 121-132, 1998.

TENNYSON, S. Economic institutions and individual ethics: a study of consumer attitudes toward insurance fraud. Journal of Economic Behaviour \& Organization, v. 32, n. 2, p. 247-265, 1997.

VÁSQUEZ, A. S. Ética. 15ª ed. Rio de Janeiro: Editora Civilização Brasileira, 1995.

VALLS, A. L. M. O que é ética. São Paulo: Editora Brasiliense, 1994.

WEIGEL, R. H.; HESSING, D. J.; ELFFERS, H. Tax evasion research: a critical appraisal and theoretical model. Journal of Economic Psychology, v. 8, n. 2, P. 215-235, 1987. 